\title{
Philosophiques
}

\section{Chartrand, Luc, Duchesne, Raymond, Gingras, Yves, Histoire des sciences au Québec, Montréal, Boréal, 1987, 487 p.}

\section{Jacques G. Ruelland}

Volume 15, numéro 2, automne 1988

URI : https://id.erudit.org/iderudit/027058ar

DOI : https://doi.org/10.7202/027058ar

Aller au sommaire du numéro

Éditeur(s)

Société de philosophie du Québec

ISSN

0316-2923 (imprimé)

1492-1391 (numérique)

Découvrir la revue

Citer ce compte rendu

Ruelland, J. G. (1988). Compte rendu de [Chartrand, Luc, Duchesne, Raymond, Gingras, Yves, Histoire des sciences au Québec, Montréal, Boréal, 1987, 487 p.] Philosophiques, 15(2), 483-484. https://doi.org/10.7202/027058ar d'utilisation que vous pouvez consulter en ligne.

https://apropos.erudit.org/fr/usagers/politique-dutilisation/ 


\section{COMPTES RENDUS}

CHARTRAND, LUC, DUCHESNE, RAYMOND, GINGRAS, YVES, Histoire des sciences au Québec, Montréal, Boréal, 1987, 487 p.

$$
\text { par Jacques G. Ruelland }
$$

Léon Lortie déplorait un jour l'absence d'un ouvrage relatant l'histoire des sciences au Québec depuis les débuts de la colonisation. Le livre de MM. Chartrand, Duchesne et Gingras comble magistralement cette lacune. Alors que plusieurs auteurs estiment que l'ère scientifique au Canada français a déburé avec le $\mathrm{XX}^{\mathrm{e}}$ siècle, les auteurs de l'Histoire des sciences au Québec n'hésitent pas à montrer le grand intérêt des premiers colons envers la découverte et la culture scientifique dès le XVI ${ }^{e}$ siècle, intérêt sans lequel la recherche scientifique n'aurait jamais pu voir le jour au Québec. On découvre ainsi des noms peut-être déjà connus, mais que l'on n'osait pas toujours assimiler à un quelconque progrès scientifique au Québec.

Le principal obstacle épistémologique à vaincre ici est l'anachronisme. Il est facile de juger d'un progrès scientifique du XVI ${ }^{e} s$. avec les normes du $\mathrm{XX}^{\mathrm{e}}$. On est ainsi porté à dénigrer l'entreprise de découverte qui constitue la base même de l'induction propre à la méthode scientifique d'autrefois. Les auteurs de l'Histoire des sciences au Québec évitent ce piège, et remettent chaque chose dans le contexte approprié. C'est dans cet esprit que l'on est amené à apprécier aussi bien les encouragements prodigués au XVIII ${ }^{e}$ s. par le marquis de La Galissonière à la cueillette d'échantillons (minerais, végétaux, animaux) et à leur envoi en Europe, que les positions des Jésuites de Québec en faveur du système copernicien cinquante ans avant la levée par le Vatican (en 1822) de l'interdit pesant sur ce système depuis 1616 , et à voir dans ces détails la manifestation certaine d'un véritable esprit scientifique : celui qui sait dire non à l'immobilisme de la vérité éternelle.

En douze chapitres, les auteurs rassemblent une documentation considérable et fort dispersée ; leur premier mérite est d'y metrre de l'ordre après le tri et l'évaluation de chaque élément. Travail d'historiens s'il en est un, qui ne se borne pourtant pas à dater les divers événements, mais qui consiste surtout à écrire une bistoire, c'est-à-dire à interpréter la signification spariotemporelle de chaque pièce dans un ensemble, en vue de la démonstration d'une hypothèse: celle qui affirme que les sciences ont, au Québec, une 
histoire qui leur est propre et qui dépend essentiellement de l'accueil que leur réserve la population québécoise - francophone et anglophone - à travers les âges. Ce livre est donc plus qu'une simple histoire des disciplines scientifiques, il est aussi l'histoire de la culture scientifique et de l'intérêt des Québécois pour toutes les questions relatives à la science; il est, somme toute, l'histoire des sciences au Québec à travers toutes les instances du processus d'institutionnalisation : écoles, universités, sociétés savantes, organisations internationales, revues, journaux, bibliothèques, musées, vulgarisation scientifique, présence de savants au Québec, controverses auxquelles ils participent, etc., le tout étant replacé dans le contexte sociopolitique et culturel approprié à chaque cas.

L'ouvrage, qui se présente comme un manuel universitaire, est doté d'un index, d'une table des matières très détaillée, d'une bibliographie sommaire et de nombreuses notes. Il est, sans conteste, le premier ouvrage du genre à donner un panorama de l'histoire des sciences au Québec; mais il a surtout la qualité de susciter la fierté légitime des Québécois pour leur contribution au développement scientifique, contribution qui a trop souvent été reléguée à l'arrière-plan, dépréciée ou simplement ignorée par les historiens. Ce livre, à peine édité, fait déjà figure de classique dans le domaine de l'histoire des sciences. C'est pourquoi, même si l'on y décèle des lacunes - certaines contributions de savants, quoique mentionnées, ne sont pas analysées en profondeur ; certains noms peuvent avoir été omis ou oubliés ; - il ne faut pas y voir quelque négligence, mais simplement le fait que l'objet du livre est de tracer non pas un portrait encyclopédique et exhaustif des sciences au Québec, mais une grande fresque qui replace les sciences dans l'histoire générale du Québec. C'est dans ce sens-là que cet ouvrage contribue luimême, à la fois par sa facture, son contenu et son impact, au développement des sciences au Québec et au rayonnement de celui-ci dans le monde.

Département de Pbilosophie, Collège Édouard-Montpetit

Département d'Histoire, Université de Montréal 